\title{
SHARING STORIES AND BUILDING RESILIENCE: STUDENT PREFERENCES AND PROCESSES OF POST-PRACTICUM INTERVENTIONS.
}

\author{
Melissa Cain, Anh Hai Le, and Stephen Billett (Griffith University, Australia)
}

\section{Post practicum interventions: Student preferences}

To graduate occupationally-informed and work-ready graduates, the Australian higher education sector has increasingly incorporated work-integrated learning (WIL) components into degree courses. These components can take many forms such as practicums, clinical experiences, and internships. They play an essential role in bridging the content studied at universities and professional social practice experienced in the workplace. With reference to the health care sector, Courtney-Pratt et al. (2012) describe the significance of clinical placements as being "undisputed as a key to professional competence" (p. 1381). It is understood, however, that the provision of these experiences alone will be insufficient to realise their full educational potential. Indeed, in enacting the provision of those experiences, the deliberate process of securing the integration of these two sets of experiences and students' reconciliation of them requires particular actions and engagement by learners (Billett, 2009). As a consequence, attention is now being given to the kinds of curriculum and pedagogical considerations required to secure that integration, and realise the full benefits of these experiences. There are good reasons to want to realise those benefits, because they come at considerable personal and institutional costs. In some instances, students are charged with finding and organising their own WIL placements. But, primarily, it is the higher education institutions that direct considerable resources, time, and funding towards sourcing and facilitating these experiences. Then, there are the contributions made by employers in terms of their time and resources in providing these experiences, and increasingly educational institutions are supporting, and sometimes paying for, students' practicum experiences. Added to this, is the considerable investment of students as they engage in these experiences and in doing so also commit considerable time, resources and often incur financial costs. Therefore, along with evaluating the effectiveness of experiences that workplace learning provides, it is also necessary to consider how interventions can best secure the integration of those experiences into the higher education curriculum and achieve strong student learning outcomes. The focus here is on how the educational potential of these experiences can be enriched through interventions after students have had or completed their work experiences: post-practicum experiences.

In the past, post-practicum reflective self-assessments have provided some insight into the usefulness of work placements. However, higher education students typically receive little guidance on undertaking reflective practice (Ryan \& Ryan, 2013), with significant differences and variations in explicit teaching of reflective practice between disciplines and institutions. This type of self-assessment often ends up being descriptive, which, while useful in its own way, is insufficient to appraise the impact the placement has on learners and others (e.g. workplace) critically. Moreover, there exists little evidence in the literature about how post-practicum interventions can be guided to make the placement experience more potent and secure important associations between the worlds of study and work. Given that the focus here is on students' practicum experiences, and how they experience and learn through them, it is particularly important to understand these phenomena from the perspective of the students. It is they who engage in these experiences, seek to reconcile what they encounter in the workplace with what they are seeking to learn through their university courses and then apply that knowledge subsequently once employed beyond graduation. All too often, the student perspective is underplayed and undervalued. Education programs and their attendant experiences are designed taking into account a range of factors, and in this complex and demanding process. Frequently, however, the perspectives of those who are to 
participate in and learn through them are not being gauged or used to inform what is being planned and enacted.

In an attempt to partially redress that circumstance and provide a basis to consider the provision of post-practicum experiences, this chapter reports on the preferences of 365 higher education students in Australia undertaking work placements in health and social care disciplines. The students were respondents to a survey that elicited a range of data about them, and how post-practicum interventions might best assist them to learn more about their prospective occupations. Having discussed the importance of postpracticum interventions, the design and administration of this survey is described, and then the findings are presented and discussed. The data presented illustrate these students' preferences for the types, forms, and timings of post-practicum interventions and their justifications for these choices. As well as quantitative measures qualitative data have been elicited and analysed. Perhaps most noteworthy, but in some ways not surprising, is a pattern of preferences for educational processes to be facilitated by teachers or experts over student-organised interventions. That is in some ways antithetical to educators' goals for their students to develop necessary skills in organising and directing their own processes of development, as will be required in practice, over expressed guidance from and validation of their learning by more informed others (i.e. clinicians and teachers). Hence, expectations that these processes would inevitably lead to students being self-directed or independent, as is often a stated goal, were inconsistent with student preferences. Variations in responses between discipline areas provide additional important information about how best to augment and support placement experiences. All of this is discussed below.

In making its case, the chapter progresses by first discussing the focus on post-practicum educational interventions. In doing so, it notes that the available literature provides little guidance in terms of the purposes of or the means of progressing with post-practicum interventions in higher education. The approach undertaken in conducting this survey and analysing the data is outlined followed by the presentation and discussion of that data, including some implications for planning and enacting postpracticum experiences within contemporary higher education.

\section{Post-practicum experiences}

The importance of engaging educationally with students after their practicums has been recognised and addressed by studies indicating that, in particular, securing feedback from students, academics, and industry professionals provides useful kinds of interventions (Billet, Cain \& Le, 2015; Maire, 2010). However, the advice about post-practicum interventions in current literature is quite limited. What is advanced in that literature can be categorised into two themes. Firstly, work placements are highly valued by students for linking occupational knowledge taught in education settings, with the requirements for practice, and also in assisting students to meet graduate outcomes and industry standards. This is often referred to as the overcoming the theory-practice divide (Mayer, 2005). The concern addressed here is that each of these settings generates particular kinds of knowledge and the task is to bring them together in some way. An assumption here is that something called theory (i.e. facts, concepts and propositions-what we know) is learnt in educational institutions and that something called practice (i.e. how to achieve goalswhat we can do) is secured through workplace experiences. On its own terms, this issue stands as a goal to be addressed. Secondly, there are themes associated with reflection-in-action and reflection-on-action (Schön, 1983) by students in which workplace experiences serve as the vehicle for engagements with and decision-making about practice. These themes are aligned with the broad educational goals of: i) the need to transform students' experiences into adaptable occupational knowledge, ii) reconciling and aligning that learning with students' educational programs' objectives; and iii) sharing, comparing and critically appraising those experiences, which initiates ways to redress difficult or confronting learning experiences and capitalise on their educational worth. 
Several studies identified from higher education literature explicitly state the importance and identify value of students reflecting on their work experiences both during and after practicums, and offer means for this to occur. Professional development logs generated by engineering students while on work placements have been shown to be effective as an assessment tool (Doel, 2008). In this case, students were provided with purposeful scaffolding through a two-day workshop prior to their placements. Feedback on the effectiveness of logs was secured through surveys and focus groups, and furnished evidence that this approach encourages students to analyse incidents at a deeper level, rather than just describing what had occurred. Post-practicum feedback from health care students undertaking learning circles and reflection tasks has also been found to provide a focus for students to appraise how their clinical experiences contribute to their occupational socialisation and identity formation (Walker et al., 2013; Coward, 2011). Through evaluating experiences by generating individual journal entries and peer debriefing sessions, it has been shown that students can identify key learning outcomes from their clinical experiences, and clinical educators are can utilise this feedback to provide more effective learning experiences (Stockhausen, 2005). Such appraisals are seen as critical to professional development and learning as carefully structured educational tasks can assist students to identify links between propositional knowledge (i.e. facts, concepts and propositions) and the requirements for and actualities of practice, and reveal and address other issues that concern or challenge them (Dean \& Clements, 2010).

For these interventions to be effective, the structure and facilitation of such appraisals must be carefully aligned with course learning outcomes and assessment items. For instance, commerce students requested to make daily elogs as a means of appraising key areas of their placements, viewed this task as irrelevant or a waste of time as these entries lacked alignment with assessment tasks (Dean, Sykes, Agostino, \& Clements, 2012). A structured approach was also recommended for the kinds of reflective practice being undertaken by Swedish nursing students to make appraisals about the effectiveness of the clinical placement model (i.e. theoretical basis, purpose, structure and design) (Lindgren, Brulin, Holmlund, \& Athlin, 2005). A focus on students developing critical thinking skills to gain a deeper awareness of self and others by reflecting on specific incidences encountered in their practicums was aimed to be realised through this kind of structuring. This practice is held to be analogous to clinical supervision processes and group supervision and reflection also serves to support students' learning during their placements. Postplacement feedback from students and industry partners is also highlighted as providing a means through which to refine courses in rapidly changing areas such as information technology (Holt, Mackay \& Smith, 2004). Structured and directed efforts press students to appraise what they have experienced actively and when those efforts are directed to achieving identified outcomes they offer the potential to be effective in achieving a range of associated educational outcomes.

Elsewhere, findings from case studies (Macleod et al., 2012) led to interventions such as the development of models for effective practice, and working towards providing more effective experiences for international students. The process and outcomes of four post-work placement seminars for chiropractic students completing a voluntary placement in Siliguri, India provides one example (Maire, 2010). In these seminars, students shared experiences of different practices encountered whilst on placement. They made explicit links between their experiences and what was taught in classes, and challenged other students to think critically about orthodox chiropractic practices in diverse settings. In another example, the potential impact of reflective practice as post-practicum experiences was highlighted by student contributions to a clinical legal education program (Curran, 2004). Through engaging in 'debriefing' sessions, students considered and appraised their learning experiences during weekly placements within disadvantaged communities. As a result, student-initiated law reform resulted in a positive change in these communities and also directly impacted future placement experiences. Similarly, the dimensions of student workplace learning in journalism internships were discussed (Forde \& Meadows, 2011). Feedback from post-placement sessions, individual interviews, and student focus groups contributed to evaluating the relevance of content and effectiveness of assessment, and industry partners' perspectives about these 
internships. This prompted refinements to the current internship model. These examples highlight the use of interventions before, during, and after practice-based experiences, as 'workplace variability' (i.e. vastly different individual experiences in similar placements) was evident in student feedback and which influenced the enactment of the intended curriculum (i.e. what was supposed to occur), design, and the kinds of pedagogic practices that can and might be selected to be utilised (Billett, 2015).

Post-practicum experiences have also been shown to address short-comings of experiences in practice settings, including the opportunity for students to share, reflect upon, and critically appraise their experiences, as being central to developing students' occupational capacities. This prompted recommendations for future intervention strategies including peer mentoring, peer teaching to assist the development of clinical reasoning skills, and critical reflection (Nash 2012; Levett-Jones, Gersbach, Arthur \& Roche, 2011). The experiences of dentistry students reveal a need for a stronger focus on outcomes-based programming within work placements in which all stakeholders have clear understandings about what is aimed to be achieved through practicum experiences (Owen \& Stupans, 2008). This study led to recommendations about the development of a national repository of experiential placement learning and assessment tasks, standardised developmental descriptors related to competencies at several levels, and the listing of benefits of collaborative engagement to identify quality placement success indicators (Owen \& Stupens, 2008). Research within nursing revealed a need for further consultation and better communication with universities regarding the allocation of student placements, as poor organisation and communication between universities and clinical facilities was found greatly to impact the success of placements, which can be addressed through the provision of post-practicum experiences (Peters, Halcomb \& McInnes, 2012). This study also identified that, although students had completed prerequisite studies prior to their placements, they were still sometimes unable to connect the knowledge they learnt in educational institutions with the requirements to practice and were inadequately prepared for the practical component of their placements.

Specific post-practicum feedback reported in the literature has also been used to identify specific issues for educational interventions. As work-integrated learning experiences are situationally, socially, and culturally embedded, accounts that evidenced and illuminated dissonance or 'culture shock' for both domestic and international students in some workplace settings were important (Macleod et al., 2012). Students reported experiencing situations in which their cultural mores were confronted inducing stress and anxiety, which could have been addressed or at least reconciled through preparatory processes and also post-practicum interventions. A project on health ethics education presents an account of the challenges for students to address ethical issues associated with culturally-divergent approaches, beliefs, and values (Fuscaldo, 2013). Case studies demonstrate how ethical principles, as taught in university courses, may clash with the cultural and religious values of patients and their families. Here, postplacement engagements emphasised that Western health ethics are not (always) cross-culturally applicable and that students need decision-making capacities to assist them to adapt ethical principles to specific cultural contexts. Hence, post-practicum interventions can be used to mediate personal experiences to develop these kinds of capacities. The outcomes of these activities all suggest that post-practicum seminars of some kinds offer a means to promote greater and more focused integration of experiences in educational and workplace settings, and to generate effective and critical learning experiences for higher education students.

In sum, whilst these accounts are helpful and informative about the potential utility of postpracticum interventions, the literature focussing specifically on those interventions is limited in quantum and scope. What it emphasises is the salience of having post-practicum interventions variously to support and extend the learning from workplace experience, address limitations of those experiences and respond to secure greater educational worth, such as making explicit links to what is being taught in students' courses and even critiquing the approach taken. Mentioned frequently were appraising and comparing experiences of occupational practice, peer-based discussion and the use of logs. Strategies such as de-briefs 
and feedback also featured in this literature. What is noteworthy is that many of the issues identified in the students' survey data (see below) were not addressed in this literature thereby highlighting the limits of its scope and, therefore, its contributions. With the exception of Forde and Meadows (2011) and Maire (2010), there was an absence of accounts of post-practicum classroom based activities. That is, the array of potential classroom-based activities was largely absent in the studies reported in that literature. In particular these studies provide evidence of post-practicum interventions' importance, yet only hint at how they might be made effective, and say little about how students might want and need to engage with these interventions.

Consequently, the findings of the survey reported below, which identify students' preference for the purpose and enactment of those interventions stands to provide insights that are not currently available in the literature.

\section{Approach}

The approach adopted for the study was to undertake a survey of health care students who had already engaged in practicums and, as such, were informed about these experiences. The survey items were developed through a process of collegiate engagement with participants who teach in university programs and are represented in this volume, and through trialling them with a small cohort of students. Through this process, the survey instrument was revised and refined, and then ultimately administered across a range of higher education institutions.

\section{Survey}

The survey instrument comprises three sections. The first section captures demographic information about participants, their gender, age groupings, the disciplines in which they are enrolled, level of study, and current year of study. The second section consists of 11 items measuring levels of interests on the educational purposes of intervention on a 5 -point Likert scale, ranging from 1 (Very interested) to 5 (Irrelevant). The reliability result with Cronbach alpha of .925 suggested very high consistency of responses across items. The third section comprises three sub-sections associated with (i) suggestions for timing of interventions; (ii) identifying the preferences for 16 different interventions on a 5-point Likert scale ranging from 1 (High Preference) to 5 (Would not participate); and (iii) ranking the importance of intervention features via 14 items ranging from 1 (Essential) to 5 (Irrelevant). In both sections, participants were given the opportunity to further comment on the sets of intervention-related items.

\section{Procedures}

The survey described and reported here is an element of a larger project that aimed to understand how best to augment higher education students' experiences in workplace settings. This was achieved through sub-projects identifying, trialling, and evaluating a range of educational interventions (i.e., teaching and learning strategies) that were implemented after students completed their practicums across different settings within the healthcare sector. The survey instrument, as noted, was developed initially with suggestions from the project team members identifying sets of items, including a range of educational purposes, important features of such interventions, and the processes that might be enacted through these interventions. These sets of items were piloted with a small group of students and refinements undertaken to improve the comprehension of these items. The survey was administered online to students across six Australian universities. Students were invited to participate via email invitations with the embedded link to the survey. Descriptive analyses were conducted with the collected data using SPSS version 24. In addition to the quantitative data, qualitative inquiry allows for in-depth exploration of perceptions and a fuller understanding of students' lived experiences on their practicums. Qualitative statements were analysed and summarised manually with trends and common themes colour coded. In this way, the qualitative data add nuances to the patterns proposed through the quantitative analysis analyses of the survey data. 


\section{$\underline{\text { Respondents }}$}

As shown in Table 1, the respondents were overwhelmingly female (81.4\%). Whilst they represented a range of healthcare disciplines, predominantly they were from nursing $(44 \%)$, followed by medicine (29.6\%), midwifery (10.3\%), and various allied health disciplines (16.1\%) such as dietetics, physiotherapy, pharmacy, occupational therapy, speech pathology, and exercise science. Such gender distribution represents the overall health care workforce (Workplace Gender Equality Agency, 2016) but is under representative of the gender distribution across Australian higher education.

Table 1

Demographic background of the respondents

\begin{tabular}{lccc}
\hline Variables & Values & $\mathbf{N}$ & $\%$ \\
\hline Gender & Female & 288 & 81.4 \\
& Male & 66 & 18.6 \\
Age & $15-19$ & 19 & 5.4 \\
& $20-29$ & 206 & 58.4 \\
& $30-39$ & 70 & 19.8 \\
Disciplines & 40 and over & 58 & 16.4 \\
& Nursing & 157 & 44.1 \\
& Medicine & 109 & 30.6 \\
& Midwifery & 38 & 10.7 \\
\hline
\end{tabular}

The findings are presented below beginning with a discussion of results relating to responses from the cohort as a whole using frequencies. The representation of the respondents of the cohort fall under four disciplinary categories: nursing, midwifery, medicine, and allied health. The data from these groups of respondents were then accessed, using Chi-squared statistics thus allowing a comparison of response patterns between these respondent groups.

\section{Student preferences for post-practicum interventions}

The findings described and discussed here are those associated with: i) educational purposes; ii) important features of post-practicum interventions, and iii) timing and process of post-practicum interventions.

\section{Educational purposes}

The respondents were asked to indicate their preferred educational purposes for participating in postpracticum interventions from a listing provided in the survey. This listing of purposes had been generated by a series of discussions by members of a large national teaching grant focused on the provisions of postpracticum experiences (Billett, Cain, \& Le, 2017). This listing was generated, circulated, and refined through discussion and then as part of the trialling process. Table 2 presents the frequencies of responses in percentages arranged hierarchically on the basis of the aggregated responses. The preferred purposes were aggregated from the frequency of responses to the three measures of interest (i.e. very interested, some interest, and interested). These three measures are used here as indications of trends or patterns within the overall data. In the left column of Table 2, the ordering of the purposes on the basis of frequency by which informants classified them as being very interested. In the column to its right are the numbers of informants, first, and then the three measures of interest. In the right-hand column is the aggregated total of these three measures. The two categories (not interested and not applicable) not included in this table can be seen to constitute between $5 \%$ and $12 \%$ of the total participants.

Table 2

Results of responses to preferences for educational purposes of post-practicum interventions

\begin{tabular}{lllllll}
\hline Educational purposes & & & & \% of responses \\
Aggregated
\end{tabular}




\begin{tabular}{|c|c|c|c|c|c|}
\hline & & & & & total \\
\hline $\begin{array}{l}\text { Make informed choices about career, work options or } \\
\text { specialisations }\end{array}$ & 348 & 52.6 & 26.7 & 15.5 & 94.8 \\
\hline Linking what is taught at university to practice & 348 & 47.7 & 31.3 & 15.8 & 94.8 \\
\hline $\begin{array}{l}\text { Improve the experience for the next cohort of } \\
\text { students undertaking practicum in that venue }\end{array}$ & 344 & 42.4 & 32.8 & 19.5 & 94.7 \\
\hline $\begin{array}{l}\text { Identify how these experiences can make you more } \\
\text { employable }\end{array}$ & 348 & 50.0 & 28.7 & 15.8 & 94.5 \\
\hline $\begin{array}{l}\text { Learn how your preferred occupation is practiced in } \\
\text { across different work settings }\end{array}$ & 346 & 45.7 & 30.1 & 18.2 & 94.0 \\
\hline Learn more about your preferred occupation & 349 & 49.0 & 27.5 & 17.2 & 93.7 \\
\hline Secure feedback on your workplace experience & 346 & 49.4 & 28.2 & 15.6 & 93.2 \\
\hline $\begin{array}{l}\text { Discuss experiences during placement you found } \\
\text { worthwhile/ interesting/ confronting }\end{array}$ & 346 & 38.4 & 30.9 & 23.7 & 93.0 \\
\hline $\begin{array}{l}\text { Linking your work experiences with course work and } \\
\text { assessments }\end{array}$ & 349 & 41.8 & 32.7 & 17.8 & 92.3 \\
\hline $\begin{array}{l}\text { Learn about other students' experiences during their } \\
\text { practicum }\end{array}$ & 348 & 29.6 & 31.9 & 29.3 & 90.8 \\
\hline $\begin{array}{l}\text { Make choices about selection of subsequent } \\
\text { courses/majors }\end{array}$ & 343 & 38.8 & 30.3 & 19.2 & 88.3 \\
\hline
\end{tabular}

Note: $\mathbf{V} \mathbf{l}=$ Very Interested, $\mathbf{S I}=$ Some Interest, $\mathbf{I}=$ Interest

The most frequently preferred purposes were associated with being informed about career choices including specialisations $(94.8 \%)$, linking theory to practice $(94.8 \%)$, improving the experience for the next student cohort (94.7\%), and identifying experiences leading to employability (94.5\%). Other purposes receiving strong focus of interest include learning about preferred occupations (93.7\%) and how this is practiced within different settings (94\%), and securing feedback on individual performance (93.2\%). The reported preferences are not surprising and aligned with the rationale of having practice-based experiences included in higher education courses. That is, they were judged to provide experiences that prepare students for a smooth transition to productive employment in workplaces and developing applicable capacities that cannot be learnt through experiences solely confined to educational settings. Thus, the overall preferences were associated with enhancing students' understanding about their selected occupation, their successful engagement with it during practicums, and how they are individually progressing towards being prepared to be effective in professional practice and its relation to fulfilling the requirements for the successful completion of their university courses.

When examining the responses from perspectives of respondents from different disciplinary categories, significant differences were observed on all 11 items relating to educational purposes of postpracticum interventions. An interesting pattern was associated with the nursing and the midwifery groups generally indicating very high level of preference (very interested option) for most purposes in comparison to the medicine and the allied health cohorts. Table 3 selectively presents some sampled items for discussion of different response patterns amongst the sub-cohorts. Like Table 2, it presents the frequencies of responses in percentages arranged hierarchically on the basis of the aggregated responses. However, some statistical measures are also included here to demonstrate the significance.

Table 3

Results of responses to preferences for educational purposes by field of study

\begin{tabular}{|c|c|c|c|c|c|c|c|}
\hline \multirow[b]{2}{*}{ Educational purposes } & \multirow[b]{2}{*}{$\begin{array}{l}\text { Field of } \\
\text { study }\end{array}$} & \multicolumn{5}{|c|}{$\%$ of responses } & \multirow[b]{2}{*}{$p$} \\
\hline & & $\mathbf{n}$ & VI & SI & I & $\chi_{12}^{2}$ & \\
\hline \multirow{4}{*}{$\begin{array}{l}\text { Linking what is taught at university to } \\
\text { practice }\end{array}$} & Nursing & 153 & 58.8 & 26.8 & 13.1 & 54.51 & $.000 * * *$ \\
\hline & Midwifery & 38 & 55.3 & 31.6 & 10.5 & & \\
\hline & Medicine & 107 & 38.3 & 39.3 & 18.7 & & \\
\hline & $\begin{array}{l}\text { Allied } \\
\text { Health }\end{array}$ & 50 & 28.0 & 28.0 & 22.0 & & \\
\hline Identify how these experiences can make & Nursing & 152 & 64.5 & 22.4 & 10.5 & 45.51 & $.000 * * *$ \\
\hline you more employable & Midwifery & 38 & 52.6 & 34.2 & 7.9 & & \\
\hline
\end{tabular}




\begin{tabular}{|c|c|c|c|c|c|c|c|}
\hline & Medicine & 107 & 29.9 & 41.1 & 23.4 & & \\
\hline & $\begin{array}{l}\text { Allied } \\
\text { Health }\end{array}$ & 51 & 47.1 & 17.6 & 21.6 & & \\
\hline \multirow{4}{*}{$\begin{array}{l}\text { Secure feedback on your workplace } \\
\text { experience }\end{array}$} & Nursing & 152 & 65.8 & 19.1 & 11.8 & 46.18 & $.000 * * *$ \\
\hline & Midwifery & 38 & 50.0 & 39.5 & 7.9 & & \\
\hline & Medicine & 106 & 34.9 & 39.6 & 18.9 & & \\
\hline & $\begin{array}{l}\text { Allied } \\
\text { Health }\end{array}$ & 50 & 30.0 & 30.0 & 26.0 & & \\
\hline
\end{tabular}

Note: $\mathbf{V I}=$ Very Interested, $\mathbf{S I}=$ Some Interest, I=Interest; ${ }^{* * *}$ denotes $\mathrm{p}<.001$

As shown in Table 3, significant difference was found on item $2\left(\chi^{2}=54.51, d f=12, N=348, p<0.001\right)$. Most of the nursing $(58.8 \%)$ and midwifery $(55.3 \%)$ respondents indicated that they were very interested in the purpose of linking theory to practice. Medicine (38.3\%) and allied health (28\%) showed lower levels of similar sentiments. Similarly, significant difference was observed on item $8\left(\chi^{2}=45.51, d f=12, N=348, p<\right.$ $0.001)$ indicating that although the majority of the nursing $(64.5 \%)$ and midwifery $(52.6 \%)$ students indicated their preference for purposes relating to identifying experiences leading to employability, a lower level of interest was indicated by the medicine sub-cohort (29.9\%). Learning about preferred occupations received very high levels of interest from $62.1 \%$ of the nursing students and $50 \%$ of the midwifery students, yet was only of high level of interest with $34.6 \%$ of the medicine respondents. The same pattern was found on item 6 , securing feedback on individual performance, between the nursing (65.8\%) and midwifery (50\%) and the medicine $(34.9 \%)$ and allied health (30\%) groups. These findings showed that there were distinct patterns of preferences among respondents from different health disciplines with those from nursing and midwifery giving stronger indication of their preferred purposes when compared to the medicine and allied health sub-cohorts.

In addition to the set of pre-determined purposes, the respondents were given the opportunity to express their opinions on the primary purposes for post-practicum interventions. The most common responses reported by this cohort comprised: to align university studies, theory, and academic literature with what they had experienced in practice; to debrief or discuss specific or unusual incidences that happened on placement; and to share and learn from a collective range of experiences.

\section{Nursing}

Nursing students reported post-practicum sessions as a means to discuss the "good and bad" aspects of placements, and respond to suggestions for improvement. Interventions would "provide a safe space to talk about concerns, share positive experiences, and consolidate learning". The respondents indicated that they valued the advice and perspectives of their tutors and peers, and saw such interventions as rich opportunities to "problem solve, challenge current beliefs, debate, and question our practice".

Respondents recognised that their placements could not provide exposure to all clinical situations, therefore, they demonstrated interest in learning from other students whose experiences differed to their own. Nursing students wanted to compare and contrast their experiences with those of their peers, to get an idea whether theirs was a typical placement, and whether they responded to clinical scenarios in alignment with their cohort (cf Peters, Halcomb \& McInnes, 2012). It was important for these students to critically appraise whether they were adequately prepared for placement and learn more about expected professional conduct. Some of the nursing students stated they would like to "develop skills to cope with challenging situations" and alleviate fears about encountering "negative workplace culture" such as instances of bullying and being treated with lack of respect. Others viewed the purpose of post-practicum interventions as a conduit between the clinical placements and academic life. They expressed a need for assistance to "get back into the swing of university life" and prepare for upcoming assessments after placements. The perceived purpose of these interventions was not only to benefit the current cohort, but also to provide helpful feedback to the university, to improve on pre-practicum training, and add value to future placement experiences for all students. In this way, the qualitative data add nuances to the patterns proposed through the quantitative analysis analyses of the survey data. 


\section{Medicine}

The main purpose medical students identified was to "consolidate knowledge and engage with peers and teachers". Debriefing on particular clinical events and the way these were managed on placement was advanced as an important theme. Respondents want to link theory with "real life" events, increase their overall skills base and receive feedback from knowledgeable others on their performance. Medical students also saw interventions as a time to share "interesting cases" that not everyone would have experienced whilst on placement, and as a general opportunity to learn from their peers. Medical students were keen to "provide tips to the next batch of students" and "recommend improvements for subsequent rotations" for the benefit of future students in general. As with the nursing students, discussing ways to cope with negative aspects of hospital work culture-described by one respondent as "callous" - was a priority. The medical students reported valuing opportunities to compare the quality of their experiences, and whether they were receiving "optimal placement experiences". Unpacking specific clinical situations and brainstorming appropriate responses were also mentioned as purposes for post-practicum interventions. So, although the medical students had not indicated as higher level of the need to engage in these activities, they also identified some practices that they saw as central to learning about and working effectively in healthcare settings.

\section{Midwifery}

Midwifery students indicated that the main purposes of post-practicum interventions were to discuss general experiences and debrief on "complex conditions, disappointments, and successes" in the workplace. Contrastingly, midwifery students placed significant emphasis on establishing support networks and "learning to build emotional resilience" to cope with the stresses of placements. Some respondents suggested that no other health trainees "have such intensive, demanding, and requiring-of-sacrifice placement expectations" and that the expectations on placement are "disproportionate to what is required in the workforce", thus the need for structured support systems. In this way, these data indicate that whilst these students see value in post-practicum experiences, they expressed concerns at the demanding and burdensome qualities of the continuity of care experiences that they saw as incommensurate to the learning required and what others, including doctors, were requested to fulfil.

\section{Allied Health}

Respondents from allied health disciplines reported that the main purpose of post-practicum interventions was "to discuss key things learnt on placement and experience from past students", to "learn about a range of placements from different sectors", and "to share difficult and enjoyable experiences". In this way, they came close to what was being anticipated in the post-practicum project. That is to use these experiences as platforms for sharing experiences and discussing outcomes of practicum placements. One respondent concluded that a suitable purpose would be to create an environment where students could relax and learn relaxation techniques in response to stressful practicum outcomes. Interestingly, while the informants of allied health disciplines such as physiotherapy, speech pathology and occupational therapy expressed their interest in sharing and hearing from others the experiences during placements as well as reflections on practice, those from dietetics were more concerned about enhancing employment skills as an educational purpose of post-practicum interventions. These dietetic informants called for particular activities during post-practicum interventions such as "resume writing and applying for jobs", "CV preparation", "assist students in getting jobs, or "debrief with other students re job applications and future plans". Again, these students bring perspectives that are distinct from counterparts in other disciplines.

The above analysis indicates some different response patterns across disciplines regarding preferences for educational purposes of post-practicum interventions, with the nursing student cohort being more certain and clearer about the preferred purposes as compared to the medicine and allied health groups. Nursing and midwifery students focused on comparing and contrasting experiences with their peers and developing coping strategies for difficult clinical situations, while medical students 
preferred sessions to focus on increasing their skills base by interacting with lecturers and supervisors. Some analysis was also undertaken across different age groupings. However, this did not reveal any significant differences in the patterning of student responses. It was anticipated that there might be some difference given that often in healthcare disciplines, especially in nursing education programs, students have quite different backgrounds, with some entering their studies directly from school and others already having workplace experience as enrolled nurses (who provide nursing care under the supervision of a registered nurse) and that about one third of entrants to medical programs have previously been trained in other health professions.

Overall, the data suggest that the respondents are keen to use post-practicum activities to share practicum experiences and discuss these outcomes to understand more about their occupations and how they can use these experiences to inform actions to progress towards employability. This finding is consistent with Stockhausen's (2005) observations on the importance of assisting students to develop a professional identity and contribute to their occupational socialisation and also Maire (2010) whose work highlights the value of sharing experiences.

\section{Important features of post-practicum interventions}

The respondents were also asked to indicate their preferences amongst a listing of possible features of post-practicum experiences. The students' preferences associated with these features were aggregated from responses to the three levels of importance, i.e., Essential, Very Important, and Important. Table 4 presents these data. In the left column is the listing of these features of post-practicum interventions. The responses are ordered hierarchically against the aggregated total in the right-hand column. In the column to its right is the number of respondents across these three categories and then the frequencies of responses captured as percentages that are arranged hierarchically on the basis of the aggregated responses.

Table 4

Responses to the importance of listed features of post-practicum interventions

\begin{tabular}{|c|c|c|c|c|c|}
\hline \multirow[b]{2}{*}{ Features of interventions } & \multirow[b]{2}{*}{$\mathbf{n}$} & \multicolumn{4}{|c|}{$\%$ of responses } \\
\hline & & $\mathbf{E}$ & VI & $\mathbf{I}$ & $\begin{array}{l}\text { Aggregated } \\
\text { total }\end{array}$ \\
\hline Development of coping skills for the workplace & 333 & 37.2 & 35.4 & 22.8 & 95.4 \\
\hline $\begin{array}{l}\text { Engaging with students at similar stages in the } \\
\text { program }\end{array}$ & 332 & 27.4 & 32.5 & 34.3 & 94.2 \\
\hline $\begin{array}{l}\text { Opportunity to provide feedback to the practicum site } \\
\text { about student experiences }\end{array}$ & 335 & 34.6 & 34.6 & 24.8 & 94.0 \\
\hline Development of coping skills for the workforce & 334 & 45.5 & 30.5 & 17.4 & 93.4 \\
\hline Focussed on work activities of selected occupation & 332 & 32.2 & 33.1 & 27.1 & 92.4 \\
\hline Focused on course content & 336 & 32.7 & 31.5 & 26.2 & 90.4 \\
\hline Opportunity to share and discuss with peers & 330 & 24.5 & 27.9 & 37.9 & 90.3 \\
\hline Engaging as many students' perspectives as possible & 330 & 22.7 & 30.9 & 34.2 & 87.8 \\
\hline $\begin{array}{l}\text { Opportunity to share and engage in structured } \\
\text { consideration of experiences }\end{array}$ & 329 & 20.7 & 30.4 & 36.5 & 87.6 \\
\hline Linked to assessment items & 338 & 31.7 & 31.1 & 21.6 & 84.4 \\
\hline $\begin{array}{l}\text { Engaging with students at different stages in the } \\
\text { program }\end{array}$ & 329 & 14.9 & 28.6 & 32.2 & 75.7 \\
\hline Teacher-led and implemented & 332 & 20.8 & 28.0 & 42.2 & 70.2 \\
\hline Student-led and implemented & 330 & 10.6 & 18.5 & 37.0 & 66.1 \\
\hline Engaging with students from other disciplines & 332 & 8.1 & 16.6 & 24.7 & 49.4 \\
\hline
\end{tabular}

Note: $\mathbf{E}=$ Essential, $\mathbf{V} \mathbf{l}=$ Very Important, $\mathbf{I}=$ Important

The most frequently preferred outcomes reported were: i) the development of capacities for coping in the workplace (95.4\%), ii) the engagement with peers at similar stages of their programme (94.2\%), iii) the opportunity to provide feedback to the practicum site with regard to the provided experiences (94\%), iv) the development of coping skills for the workforce (93.4\%), and v) being focused on work activities of selected occupation (92.4\%). So, the desired features of the post-practicum experiences are directed to 
quite pragmatic goals in terms of realising effective learning outcomes from workplace experiences, subsequently informing practitioners of the provided experiences for improvement. These preferences are well aligned with the anticipated outcomes for student practicum experiences, and are consonant with the findings associated with concerns and emphasis on receiving feedback on individual progress and performance (Dean \& Clements, 2010). They also align with findings by Stockhausen (2005) where students in health care disciplines see debriefing opportunities as assisting with developing a sense of professional identity and increasing personal resilience. These sources of data can inform the development of various types of post practicum intervention activities and the way in which they are conducted so as to focus on these themes.

An analysis of the response patterns among the four sub-cohort of students indicates that significant differences between disciplinary categories were observed on eight (out of 14) items. A closer examination of the response patterns indicated a clear significant difference in preferences between the nursing and the medicine sub-cohorts with respect to items 7,10 , and 14 . Table 5 selectively presents some sampled items for discussion of different response patterns amongst the sub-cohorts. In this table, the lefthand column offers these preferred features of post-practicum interventions, and the next column indicates the responses within the sub cohorts. To the right are the number of respondents to each of those sub cohorts and then their preferences. In the two right-hand columns are provided indications of significance. 
Table 5

Responses to the importance of intervention features by field of study

\begin{tabular}{|c|c|c|c|c|c|c|c|}
\hline \multirow[b]{2}{*}{ Features of intervention } & \multirow[b]{2}{*}{$\begin{array}{l}\text { Field of } \\
\text { study }\end{array}$} & \multicolumn{5}{|c|}{$\%$ of responses } & \multirow[b]{2}{*}{$p$} \\
\hline & & $\mathbf{n}$ & VI & si & $\mathbf{I}$ & $\chi_{12}^{2}$ & \\
\hline \multirow{4}{*}{$\begin{array}{l}\text { Engaging with students at similar stages in } \\
\text { the program }\end{array}$} & Nursing & 141 & 37.6 & 29.8 & 29.8 & 24.52 & $.017^{*}$ \\
\hline & Midwifery & 36 & 25.0 & 33.3 & 36.1 & & \\
\hline & Medicine & 106 & 17.9 & 36.8 & 39.6 & & \\
\hline & $\begin{array}{l}\text { Allied } \\
\text { Health }\end{array}$ & 49 & 20.4 & 30.6 & 34.7 & & \\
\hline \multirow[t]{4}{*}{ Opportunity to share and discuss with peers } & Nursing & 140 & 33.6 & 27.9 & 32.1 & 30.46 & $.002 * *$ \\
\hline & Midwifery & 36 & 33.3 & 33.3 & 22.2 & & \\
\hline & Medicine & 105 & 9.5 & 29.5 & 50.5 & & \\
\hline & $\begin{array}{l}\text { Allied } \\
\text { Health }\end{array}$ & 49 & 24.5 & 20.4 & 38.8 & & \\
\hline \multirow{4}{*}{$\begin{array}{l}\text { Development of coping skills for the } \\
\text { workforce }\end{array}$} & Nursing & 144 & 58.3 & 26.4 & 13.9 & 35.73 & $.000^{* * *}$ \\
\hline & Midwifery & 35 & 40.0 & 37.1 & 17.1 & & \\
\hline & Medicine & 106 & 34.0 & 34.0 & 23.6 & & \\
\hline & $\begin{array}{c}\text { Allied } \\
\text { Health }\end{array}$ & 49 & 36.7 & 30.6 & 14.3 & & \\
\hline
\end{tabular}

Note: $\mathbf{V I}=$ Very Interested, $\mathbf{S I}=S o m e$ Interest, $\mathbf{I}=$ Interest; ${ }^{*}$ denotes $\mathrm{p}<.05, * * \mathrm{p}<.01,{ }^{* * *} \mathrm{p}<.001$

Specifically, whereas $37.6 \%$ of the nursing students reported the engagement with peers at similar stages in their course of study as a 'very important' feature of post-practicum experience, only $17.9 \%$ of the medicine students indicated this preference. Similarly, 33.6\% of the nursing respondents highlighted the very important feature of the opportunity to share and discuss with peers as part of their post-practicum experience, only $9.5 \%$ of the medicine sub-cohorts expressed similar sentiment. With respect to the development of coping skills for the workforce, a great majority of the nursing sub-cohort (58.3\%) considered this as essential as compared to $34 \%$ of the medicine indicating similar view. So, for reasons not fully explained within the survey data there are distinct preferences amongst the sub-cohorts. This may be relate to key differences between medical and nursing educational practices.

The survey instrument also provides an opportunity for respondents to provide qualitative responses about why they believed it was important they be offered these kinds of experiences after their practicums. Overwhelmingly, students from all of the sub-cohorts reported value in learning about their peers' experiences in a range of clinical contexts, and viewed these opportunities as a means to consolidate and supplement their own knowledge and skills set. One respondent stated that these activities helped to "fill gaps-as not everything is explored in labs, and this adds real world perspective". Another agreed: "[you can] hear about different areas you may not have experienced and hear about experiences you may not have had. This is essential as everyone's experience is different". Students might be introduced to areas of the profession they may "not yet have considered that may be of interest" providing good opportunities "to share experiences to broaden [the] knowledge base". In this way, whilst there were different levels of interest across the sub-cohorts consistently, there was a common appreciation of the potential of these experiences to promote their learning through and from others' practicum experiences. There were, however, differences in the detailing of that potential across these sub cohorts.

\section{Nursing}

Nursing students reported post-practicum activities as being a helpful way to express their understanding of professional knowledge as experienced in their unique placement settings. As one student wrote: “I'm extremely happy [to go on placement] but also anxious and feel the post-practicum activities would help me to consolidate my practice/knowledge and help me to prepare for this next step". Sharing experiences would help some students decide if nursing is the right choice of profession and if they have the skills and attributes to realistically cope with the various clinical scenarios that may be encountered. Developing the 
skills of team work through post-practicum activities was also mentioned as an important outcome, with one respondent suggesting that these opportunities would "create unity in the profession" and provide much needed extra support. Other nursing respondents highlighted the importance of being able to debrief as:

... cathartic and [to ensure that] there is communication between all bodies that facilitate learning ... and a harmony between those who learn and those who teach.

Many of the nursing informants agreed that the time between practicums was too large to retain what was previously learnt and, therefore, interventions might assist to consolidate practicum experiences and link to the next placement. In this way, these nursing students were able to identify the efficacy of these experiences and the direct implications it had for their learning and development as nascent nurses. They also pointed out that, given nursing is often undertaken in teams, ways of working as nurses needed to be reflected in post-practicum types of debriefs. Indeed, much of professional practice has forms of intra-or interprofessional interaction as part of daily work activities. These students also suggested that the educational processes, including assessment, could be enhanced through the lessons learnt from postpracticum interventions.

\section{Medicine}

Medical students also placed importance on the opportunity to share and debrief, and as a "coping mechanism for challenging scenarios/conflict/ethical dilemmas", to reduce anxiety about whether they were "on the right track", and whether they were being taught "the most relevant aspects of medicine". This was expressed in several comments such as: "medical school is hard", "it can be lonely", "we need to debrief and discuss". As mentioned earlier, of prime importance medical students reported the opportunities to advance the training program and clinical experiences for future students, and to "ensure sub-optimal teaching experiences can be improved". Medical students also valued the opportunity to gain knowledge from other students who had different experiences from theirs. As one student expressed:

On clinical placement as a medical student, you are often a lone wolf. There is often not a lot of interaction with colleagues and tutors in the later years and your learning relies on informal interaction with members of the treating team.

Post-practicum interventions were seen as an important avenue for support in reducing isolation, so that students could feel "that [they] are not alone in the journey". Knowing that they were on "an even footing" with their peers and were receiving the same quality education was essential to medical students. The consequence here is that the medical students reported whilst referring to improving the educational experience also referred to the loneliness or isolation that can occur as a medical student working in a clinical setting. Again, this suggests a particular focus is of concern for these students, which are less represented in other sub-cohorts.

\section{Midwifery}

Midwifery students emphasised that opportunities to discuss placements were important "to change the way [practicums] are implemented". Like medical students, interventions were a valued way to compare experiences. This cohort wanted to "see how other work places operate, adhere to protocol, and treat students". Opportunities to share information or advice "would reduce stress and fear levels" and "support from other students that have been through the experience would be invaluable". Midwifery students also reported valuing such activities as helping to "prepare future students for a smoother transition to practicums" and as a mental health support mechanism to "know that we are not alone in our experiences". External students who have few ways to engage with their cohort on this level have found these types of opportunities lacking. Linking theory and practice was noted as another area that could be enhanced by post-practicum interventions. As one respondent explained: 
... practicum and university study don't seem to link in very well. This means often we feel unprepared for practicum with the necessary background scientific knowledge ...

Midwifery students also placed value on confirming "correct management of situations and identifying differences taught at university compared with in the clinical setting". As such, the midwifery students, who also often engage in work placements in relative social isolation looked to post-practicum interventions as a means of overcoming the challenges they face in those circumstances and supporting their learning. Once again, the midwifery data are more closely aligned with the nursing data, in that these students seek and value support and advice from their peers. While medical students also valued this type of advice they were more focused on obtaining support from their lecturers and clinical supervisors.

\section{Allied Health}

Students in the allied health disciplines placed emphasis on post-practicum interventions as a way of getting to know "what's out there", and "discover the variances" between one placement and the next. This was explained by one respondent as "not everyone is able to get to work with all types of clientele, therefore it is interesting to learn about other people's experiences based on the population of people they were working with". As with the other cohorts, the most valued aspect of such interventions is "discussing and sharing experiences is a good way to reflect on what has been done and how to improve for the future". A sharing of key cases "offers a chance to learn about these cases that do not come up during university coursework". In sum, this cohort felt it was important to "consolidate the learning experience, and to better prepare for future placements in the short term and job readiness in the long term".

In all, across these sub cohorts, the informants were able to identify issues that need to be resolved and the ways that post-practicum interventions could address those issues. They were, however, not entirely consistent across the sub cohorts and in ways that reflect the particular circumstances in which the students engaged in practicums and the nature of the clinical work in which they engaged. So, given this, it is important to understand the kind of interventions that these students believe are likely to be effective and pay attention to the nuanced differences in suggestions provided by each discipline.

\section{Interventions}

The respondents were also asked to indicate their preferences for the timing and processes of the postpracticum interventions. Figure 1 presents the results for the preferred timing of interventions.

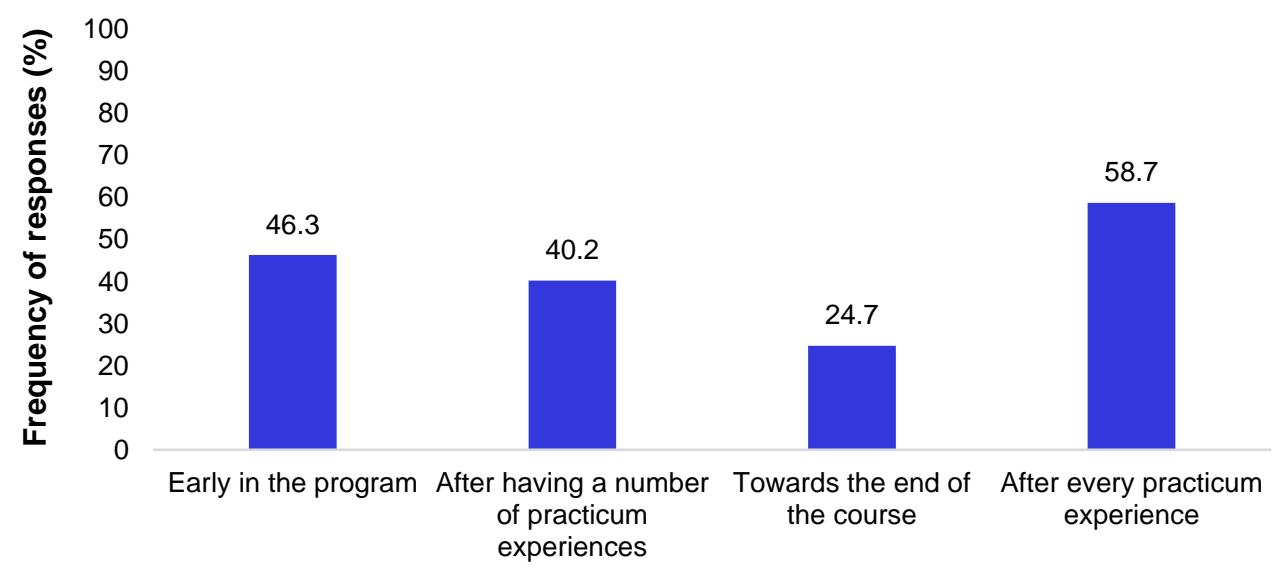

Timing of post-practicum interventions

Figure 1. Responses to the preferred timing of post-practicum interventions

The strongest preference was for interventions to occur after every practicum (58.7\%) followed by a preference for early in the programme (46.3\%), perhaps after a number of practicum experiences (40.2\%), but less preferred for these towards the end of the course (24.7\%). This suggests that the students highly value interventions after every practicum, particularly at the beginning of the programme as they can come to engage with clinical settings and tasks, and are in need of seeking guidance and securing feedback on 
their progress. This finding provides an informed basis for making decisions about the timing of these interventions.

With regard to preferences for the kinds of interventions, the patterns of responses are consistent with what has been proposed above in terms of important features of post-practicum experiences. Table 6 presents the frequencies of responses in percentages arranged hierarchically on the basis of the aggregated responses. In this table, in the left-hand column the listing of those interventions is provided and they arranged hierarchically in response to an aggregation of the degree by which the informants categorise them as being High Preference and Okay. In the column to the right, this aggregation of two of the four categories of responses (high preference, okay, low preference and would not participate) are used to indicate patterns of preference. Then, the next four columns capture the percentage of responses across the four categories.

Table 6

Results of responses to the kinds of intervention

\begin{tabular}{|c|c|c|c|c|c|c|}
\hline \multirow[b]{2}{*}{ Interventions } & \multirow[b]{2}{*}{$\mathbf{n}$} & \multicolumn{5}{|c|}{$\%$ of responses } \\
\hline & & $\begin{array}{r}\text { Aggregated } \\
\text { (HP+Ok) }\end{array}$ & HP & Ok & LP & WnP \\
\hline small groups facilitated by teachers/tutors & 337 & 85.4 & 52.2 & 33.2 & 11.3 & 3.3 \\
\hline $\begin{array}{l}\text { small groups meeting periodically facilitated by } \\
\text { placement supervisor }\end{array}$ & 335 & 81.2 & 44.8 & 36.4 & 15.5 & 3.3 \\
\hline one-on-one with teachers & 339 & 74.3 & 41.9 & 32.4 & 22.4 & 3.2 \\
\hline one-on-one with a more experienced student & 334 & 75.7 & 30.5 & 45.2 & 18.6 & 5.7 \\
\hline small groups facilitated by more experienced students & 335 & 68.7 & 29.9 & 38.8 & 21.5 & 9.9 \\
\hline shared classroom-based group activities & 334 & 63.1 & 29.3 & 33.8 & 27.2 & 9.6 \\
\hline $\begin{array}{l}\text { individually completed activity with feedback from } \\
\text { teachers }\end{array}$ & 331 & 58.3 & 26.3 & 32.0 & 32.9 & 8.8 \\
\hline small self-managed groups & 335 & 66.3 & 25.1 & 41.2 & 24.8 & 9.0 \\
\hline as part of usual scheduled class activities & 330 & 63.6 & 18.8 & 44.8 & 29.4 & 7.0 \\
\hline one-on-one with a peer & 336 & 61.7 & 18.5 & 43.2 & 28.0 & 10.4 \\
\hline a special event each semester & 330 & 49.1 & 13.3 & 35.8 & 38.5 & 12.4 \\
\hline whole of class activities & 328 & 40.3 & 11.3 & 29.0 & 38.7 & 21.0 \\
\hline online moderated by tutor & 329 & 31.9 & 9.4 & 22.5 & 36.8 & 31.3 \\
\hline one-line with peers & 329 & 27.4 & 7.3 & 20.1 & 38.6 & 34.0 \\
\hline presentations to peers & 335 & 29.0 & 6.6 & 22.4 & 42.4 & 28.7 \\
\hline something students should organise & 328 & 23.2 & 4.6 & 18.6 & 45.1 & 31.7 \\
\hline
\end{tabular}

Note: $\mathbf{H P}=$ High Preference, $\mathbf{O k}=$ Okay, $\mathbf{L P}=$ Low Preference, $\mathbf{W n P}=$ Wold not Participate

The strongest patterns of preferred interventions are those associated with small group works

facilitated by teachers/tutors $(85.4 \%)$ or by placement supervisor $(81.2 \%)$, followed by one-on-one meeting with either teachers $(74.7 \%)$ or more experienced students $(75.7 \%)$. Such preferences confirm what was proposed in the important features of interventions with respect to student concerns about individual performances during practicums, and the relation of these performances to their study and career prospects. The next group of intervention options receiving preferences from the majority of the respondents is associated with small groups facilitated by more experienced students (68.7\%), and selfmanaged groups (66.3\%). These preferences seem to emphasise the dual concerns about personalised feedback on performance and this coming from a more experienced person proving insights as an expert. Apart from the highly preferred intervention options discussed above, it is interesting to note a few options that generated the highest level of reluctance, i.e., would not participate, including online with peers (34\%), online moderated by tutor (31.3\%), something student should organised (31.7\%), and presentations to peers (28.7\%). This indicates that these interventions receive high levels of reluctance when being reported by at least $28 \%$ of the respondents.

Overall, the data across a range of healthcare disciplines indicates that interventions in small groups mediated by more experienced individual (i.e. teacher, tutor, placement supervisor or experienced student) are the most highly preferred options by the surveyed students, which is analogous to what Lundgren et al.'s (2005) claims but divergent to Nash's (2012) recommendations for the inclusion of peerled and directed activities to develop critical analysis of learning incidents. While this has important 
implications for education provisions in meeting students' needs and preferences, considerations about how such provisions might be afforded need to be taken with care. Meeting such needs and preferences is intensely resource-demanding and would be difficult to be sustained within resource-jealous higher education environments and by time-jealous teachers.

Respondents were also given the opportunity to suggest what form these interventions might take and under what circumstances. All sub cohorts indicated a preference to have interventions conducted face-to-face (not online) with a teacher or knowledgeable other present, in a comfortable and inviting environment, and to occur immediately after the placement (or within one week of the end of placement). Many others expressed a need to have regular interventions during placement or at least one opportunity mid placement. Ongoing support in the form of regular interventions is seen as a valued and particularly helpful enhancement to the placement cycle. However, and as noted previously, there were differences in these preferences across the sub cohorts.

\section{Nursing}

For all discipline groups, the most popular suggestion for how these interventions could be conducted was for small groupings of three to six students, and conducted in ways that would ensure that all students would have equal opportunities to share and respond. Nursing students wanted the primary focus to be a "sharing of stories", providing participants opportunities to "speak and be heard" and for "all to have a turn". Such discussions should be based around an "educational topic or question", which linked to evidence in practice. Outcomes might include the opportunity for structured self-reflection and for students to receive feedback from the facilitator and their peers. The group could agree, perhaps, upon a particular clinical issue that needed further improvement as a way to structure the sessions. Nursing students reported that they would like to engage with and hear from students in the year above as they value their advice and recommendations. Students want to gain a sense of how they were performing and if they were meeting professional targets. Most importantly, the majority of respondents clearly stated that these interventions needed to be informal in nature and facilitated in such a way that everyone felt comfortable and could "talk openly". Facilitators would need to provide encouragement and allow for students to find a sense of "solidarity and support" and "have fun". For the interventions to be successful, respondents stated that students must be able to "connect with others in a confidential and respectful manner" to discuss concerns experienced while embarking on their rotations. Structured problem solving activities were offered by several respondents, so participants could learn more about how others "had dealt with negative experiences and how has this impacted on their personal and work life". With this in mind, the interventions would also provide timely feedback for university staff who, the students suggested, need to be more aware of work place cultures as they were perceived as being "out of touch" with the current workplace environment. These qualitative statements are comparable to other nursing data, in that students placed emphasis on all participants being involved and benefitting from the activities and that safety and solidarity within the profession were core concerns. It is important that academic staff hear the voices of those who believe they need greater connection with the clinical workplace, so as to provide more accurate and up-to-date information about the placement experience.

\section{Medicine}

The majority of medical students also desired interventions in small groups that undertook general discussion around the successes and challenges of practicums, and led to opportunities for self-reflection. The preference was for these to be led by lecturers and placement supervisors, and for the group members to remain consistent in each intervention to "build trust and rapport". It was suggested that each group member would come to the sessions with "an interesting or challenging experience to discuss" and to identify gaps in their personal knowledge that could be addressed. One respondent suggested that participants "discuss one or more interesting patient cases with an experienced teacher to go through holistic views of the history, examination, pathophysiology, and management of the condition". Several 
respondents would like to know the positive and negative features of each rotation and gain suggested "survival tips" specific to that context. Medical students were also interested in learning more about "how to apply for training and jobs". It is evident here, that medical students placed more emphasis on having a framework and focus for each intervention, based around case studies or a topic of concern. Less emphasis on affective outcomes was noted as compared to the nursing students.

\section{Midwifery}

Midwifery students also preferred these interventions to be teacher led and in small groups, with the structure "facilitated by a professional in the field of study" with a "facilitation skill-set" and experience in such settings. There was inference that interventions in large group settings would not be as successful as some large group debriefs "get off topic or become dominated by big personalities". These interventions would be to discuss issues with a "practising professional and/or teacher who could shed light on the theory-practice gap to inform future practice". Students might share experiences through detailing "short scenarios" and asking others in the group how they might have dealt with these situations. These students felt that interventions could also include practical 'mock ups' of emergency situations which would increase their confidence to cope in such challenging times. Most importantly, each group member would be "invited to speak or be asked questions to prompt discussion". These responses are more closely aligned with those of the medical students in that suggested activities were based on scenarios or specific incidences in order to provide closer links between theory and practice.

\section{Allied Health}

Students in the allied health disciplines placed emphasis on post-practicum interventions as a way of knowing more about the various types of practicums and how their peers' experiences differed to their own. They recognised that the limited number of practicums in their degree could not possibly expose them to the diversity of clientele they would encounter as professionals and that a 'sharing of cases' would assist to broaden their knowledge in this respect. In sum, this cohort valued opportunities to consolidate the learning experience and develop a breadth of knowledge required for job readiness and employability. As for medicine and midwifery students, the respondents from allied health wished to increase their knowledge base and work readiness through the sharing of a variety of clinical cases and subsequent discussion through post-practicum activities.

\section{Implications}

Findings from the post-practicum survey indicate that students in a range of health care disciplines strongly favour the implementation of opportunities to engage with university representatives and their peers after their practicums. These students have clear notions of the main purposes of such interventions, what they would like to see addressed, and under what conditions these activities would take place. Quantitative findings revealed that the most preferred purposes were associated with being informed about career choices including specialisations, linking theory to practice, improving the experience for the next student cohort, and identifying experiences leading to employability. Qualitative responses addressed these purposes in more detail as well as placing an emphasis on comparing and contrasting practicum experiences, gaining knowledge on how best to handle specific clinical situations and negative workplace culture, and to learn more about expected professional conduct. Nursing students wanted to compare and contrast their experiences with those of their peers, to get an idea whether theirs was a typical placement, and whether they responded to clinical scenarios in alignment with their cohort (cf Peters, Halcomb \& McInnes, 2012). A frequently mentioned purpose in the comments was to improve the overall practicum experience for future cohorts by passing on 'tips' and making restructuring recommendations to the universities. These preferences are well aligned with the anticipated outcomes for student practicum experiences, and are consonant with the findings associated with concerns and emphasis on receiving feedback on individual progress and performance (Dean \& Clements 2010; Dufrene \& Young 2014). They also align with findings by Stockhausen (2005) where students in health care disciplines see debriefing 
opportunities as assisting with developing a sense of professional identity and increasing personal resilience. These sources of data can inform the development of various types of post-practicum intervention activities and the way in which they are conducted so as to focus on these themes. Overall, the data suggest that the respondents are keen to use post-practicum activities to share practicum experiences and discuss these outcomes to understand more about their occupations and how they can use these experiences to inform actions to progress towards employability. This finding is consistent with observations by Walker, Crooke, Henderson and Creedy (2013) and Coward (2011) on the importance of assisting students to develop a professional identity and contribute to their occupational socialisation and also Maire (2010) whose work highlights the value of sharing experiences.

After stating the perceived purposes of post-practicum interventions, students provided a range of desired features and outcomes of such opportunities. The most frequent responses centred on the development of capacities for coping in the workplace, engaging with peers at similar stages of the programme, and providing feedback to the workplace sites. These desired outcomes highlight the importance students place on realising effective learning outcomes from workplace experiences. Respondents elaborated on these preferences through comments which stressed the rich opportunities such interventions would provide them to learn from the experiences of others, to 'fill in the gaps' in their own understandings, gain support, decrease feelings of isolation, and identify and overcome the disjunct between suggested management of professional situations as proposed at university and in practice in clinical settings. Preferences for when and how these interventions would be conducted were offered. The majority of students preferred informal activities that involved small groups of students led by a university representative, placement supervisor, or knowledgeable other, directly after the placement finished, and in a situation that would allow participants to feel safe, comfortable, and for every person to have the ability to speak and be heard. Online options, large groups, and peer organised interventions were least favoured. Students preferred these meetings to be structured around problem solving activities, discussing interesting or challenging clinical situations, and practical advice for applying for further training and employment.

\section{Conclusions}

The overview of studies in this chapter relating to engaging with students before, during, and after their practicums is strongly supported by results from the national questionnaire given to students in nursing, midwifery, medicine, and allied health disciplines described here. These data highlight that students greatly value opportunities to engage with their peers and knowledgeable others and have clear ideas about what these intervention activities might look like and how they might be conducted. It is essential, therefore, that opportunities are provided for students to regularly debrief, reflect, and dissect specific incidences of their placement experiences and use these opportunities to consolidate theory and practice, meet graduate outcomes and industry standards, and increase work readiness. Given the nuanced data between discipline areas, it is recommended that preliminary investigations (perhaps questionnaires) be used to guide the development of post-practicum activities as (while there are commonalities) differences in expectations and needs can be used to carefully craft opportunities specific to the particular cohort. Further research into the outcomes and perceived value of post-practicum interventions (such as described in this volume) may further enhance the effectiveness of the placement experience. 


\section{References}

Australian Gender Equality Agency (2016). Gender comparison of the workforce by industry. Accessed at: https://www.wgea.gov.au/sites/default/files/Gender\%20composition-of-the-workforce-byindustry.pdf

Billett, S. (2009). Realising the educational worth of integrating work experiences in higher education. Studies in Higher Education,, 34(7), 827-843.

Billett, S. (2015). Integrating Practice-based Experiences into Higher Education. Dordrecht, The Netherlands: Springer.

Billett, S., Cain, M., \& Le, A. H (2016): Augmenting higher education students' work experiences: preferred purposes and processes, Studies in Higher Education, doi: 10.1.080/03075079.2016.1250073

Courtney-Pratt, H., FitzGerald, M., Ford, K., Marsden, K., \& Marlow, A. (2012). Quality clinical placements for undergraduate nursing students: a cross-sectional survey of undergraduates and supervising nurses. Journal of advanced nursing, 68(6), 1380-1390.

Curran, L. (2004). Responsive law reform initiatives by students on clinical placement at La Trobe law. linders Journal of Law Reform, 7(2), 287-301.

Coward, M. (2011). Does the use of reflective models restrict critical thinking and therefore learning in nurse education? What have we done? Nurse Education Today, 31(8), 883-886. doi:10.1016/j.nedt.2011.01.012

Dean, B.A. \& Clements M. (2010). Pathway for student self-development: a learning-orientated internship approach. University of Wollongong Research Online. Accessed at: http://ro.uow.edu.au/cgi/viewcontent.cgi?article=2478\&context=commpapers

Dean, B.A., Sykes, Ch., Agostinho, S. \& Clements M. (2012). Reflective assessment in work-integrated learning: to structure or not to structure, that was our question. University of Wollongong Research Online. Accessed at:

http://ro.uow.edu.au/cgi/viewcontent.cgi?article=3617\&context=commpapers

Doel, S. (2008). Fostering student reflection during engineering internships. $10^{\text {th }}$ anniversary edition of the Asian-Pacific Journal of Cooperative Education. Selected papers from the 2008 Biennial Asia-Pacific Conference on Cooperative Education, Manly, Australia.

Dufrene, C. \& Young, A. (2014.) Successful debriefing - Best methods to achieve positive learning outcomes: A literature review. Nurse Education Today 34(3), 372-376.

Forde, S. \& Meadows, M. (2011). Industry placements in journalism education: Exploring enhanced learning and professional growth for interns. Journalism Research and Education Section of IAMCR. Accessed at: http://jrejournal.com/ojs-2.3.7/index.php/jre/article/view/12

Fuscaldo, G. (2013). Addressing cultural diversity in health ethics education. Sydney: Office for Teaching and Learning. Accessed at:

http://chs.unimelb.edu.au/programs/ethics_in_human_research_practice/projects/addressing_cul tural_diversity_in_health_ethics_education

Holt, D., Mackay, D., \& Smith R. (2004). Developing professional expertise in the knowledge economy: Integrating industry-based learning with the academic curriculum in the field of Information Technology. Asia-Pacific Journal of Cooperative Education 5(2), 1-11.

Levett-Jones, T., Gersbach, J., Arthur, C., \& Roche, J. (2011). Implementing a clinical competency assessment model that promotes critical reflection and ensures nursing graduates' readiness for professional practice. Nurse Education in Practice, 11(1), 64-69. doi:10.1016/j.nepr.2010.07.004

Lindgren, B., Brulin, C., Holmlund, K. \&, Athlin, E., (2005). Nursing students' perception of group supervision during clinical training. Journal of Clinical Nursing, 14(7), 822-829. doi:10.1111/j.1365-

2702.2005.01245.x 
Macleod, C., Sweet, L., Cavaye, A., Fanning, C., Mills, D., \& Oliphont, J. (2011). Learning and leading: An innovative approach towards maximising the effectiveness of work-integrated learning at Flinders University. Ergo 1(2), August. Accessed at: $<$ http://www.ojs.unisa.edu.au/index.php/ergo/article/view/1068/758

Maire, J. (2010). Bridging the gap between learning at work and in the classroom through a structured postplacement seminar. Special Issue of the Asia-Pacific Journal of Cooperative Education Work Integrated Learning (WIL): Responding to Challenges. 103-113. Accessed at: http://www.apjce.org/files/APJCE_11_3_103_113.pdf

Nash, R. (2012). Good practice report. Clinical teaching. Sydney: Australian Learning and Teaching Council. Assessed at: https://eprints.qut.edu.au/70895/1/GPR_clinical_teaching_Nash_2011.pdf

Owen, S., \& Stupans, I. (2008). Experiential placements in Pharmacy. 'Quality indicators for best practice approaches to experiential placements in Pharmacy programs'. Adelaide: Carrick Institute, University of South Australia.

Peters, K., Halcomb, E. J., \& McInnes, S. (2013). Clinical placements in general practice: Relationships between practice nurses and tertiary institutions. Nurse Education in Practice, 13(3), 186-191. doi:10.1016/j.nepr.2012.09.007

Ryan, M., \& Ryan, M. (2013). Theorising a model for teaching and assessing reflection learning in higher education. Higher Education Research \& Development, 32(2), 244-257. doi:10.1080/07294369.2012.661702

Schön, D. (1983). The Reflective Practitioner: How professionals think in action. London: Temple Smith.

Stockhausen, L. (2005). Learning to become a nurse: Students' reflections on their clinical experiences. Australian Journal of Advanced Nursing 22(3), 8-14.

Walker, R., Cooke, M., Henderson, A., \& Creedy, D. (2013). Using a critical reflection process to create an effective learning community in the workplace. Nurse Education Today, doi:10.1016/j.nedt.2012.03.001 